Werner Köpp ${ }^{1}, \mathrm{MD}$

Felicitas Rost ${ }^{2}, \mathrm{PhD}$

Sybille Kiesewetter ${ }^{1}, \mathrm{PhD}$

Hans-Christian Deter ${ }^{1}, \mathrm{MD}$

1 University Hospital Charité Campus Benjamin Franklin, Berlin, Germany

2 University College for Psychology, London, United Kingdom

Corresponding Author: Dr. Werner Köpp, Maassenstr. 8, 10777 Berlin, Germany

THE FATAL OUTCOME OF AN INDIVIDUAL WITH ANOREXIA NERVOSA AND SHEEHAN'S SYNDROME AS A RESULT OF ACUTE ENTEROCOLITIS A CASE REPORT 
Abstract

Objectives: To illustrate the close association between a disturbed psychosocial upbringing, frequent physical illness and medical interventions. Method: We report a case of a 44-year-old woman with anorexia nervosa (AN) and Sheehan's syndrome who died as a result of a toxic cardiac arrest. Results: The patient presented with a BMI of 13.6 $\mathrm{kg} / \mathrm{m}^{2}$. She refused any intensive-care treatment and died from toxic cardiac arrest. Postmortem examination revealed an acute gastroenterocolitis. Conclusion: The history of this patient illustrates how psychological deprivation led to eating disturbances, early pregnancy, and the life-threatening delivery of twins. This resulted in a diagnosis of Sheehan's syndrome, hepatitis C and a ventricular ulcer. A psychosocial event triggered a late exacerbation of her AN. A helpful alliance between patient and staff did not occur as she rejected it.

Keywords: anorexia nervosa, autopsy, death, Sheehan's syndrome. 


\section{The fatal outcome of an individual with anorexia nervosa and Sheehan's syndrome as a result of acute enterocolitis - a case report}

Since its first description by Gull ${ }^{1}$ and Lasègue ${ }^{2}$ anorexia nervosa (AN) has been recognised as a "distinct clinical entity"3 and thus understood as a psychiatric disorder. This however changed rather suddenly after Simmonds ${ }^{4}$ published his work of anterior pituitary lesions in a patient with cachexia. Until the late 1930s it was henceforth understood as an endocrinological disease linked to pituitary failure. It took more than 20 years to correct this misleading view ${ }^{5}$ and restore its original description by distinguishing it from pituitary failure ${ }^{6-7}$. Finally Sheehan ${ }^{8}$ was able to show in 1937 that hypopituitarism is indeed not a condition of anorexic cachexia, but specifically occurs after a postpartum haemorrhagical necrosis.

There are numerous studies in the literature on the neuro-endocrinological aspects of AN and somatic comorbidity ${ }^{9-11}$. To our knowledge, however, Derman $\&$ Szabos $^{12}$ are the only authors reporting the simultaneous occurrence of AN and Sheehan's syndrome. We present a case of a death of a woman with AN and Sheehan's syndrome as a result of an acute enterocolitis. The aim of our case report is to illustrate the close association between a disturbed psychosocial development, frequent physical illness and medical interventions. 


\section{Case report}

A 44-year-old woman was transferred to the psychosomatic unit of our university hospital with a diagnosis of AN. Approximately 12 weeks previously, her GP admitted her to a psychiatric unit due to extreme weight loss. Her weight plummeted from $51 \mathrm{Kg}$ to $34 \mathrm{Kg}$ within six months. Following four weeks of unsuccessful treatment, she was transferred to the department of internal medicine where she was fed by central venous catheter. In addition, a negative helicobacter ventricular ulcer was treated. Despite all efforts, she was not able to keep her gained body weight of $37 \mathrm{Kg}$ after stopping the parenteral nutrition, and was weighing just over $33 \mathrm{Kg}\left(\mathrm{BMI}=13.6 \mathrm{~kg} / \mathrm{m}^{2}\right)$ when she arrived at our unit eight weeks later. Due to the ventricular ulcer we treated the patient in constant cooperation with the gastroenterological department.

The patient first showed symptoms of an eating disorder at the age of 12 years. She grew up in a children's home having never known her parents. Between the age of twelve and 15 she often refused the intake of food and became underweight. She started binge eating at the age of 16 and occasionally induced postprandial vomiting. The patient's own description of her eating habits at that time corresponds with a diagnosis of an atypical $\mathrm{AN}$, which was subsequently replaced by an atypical bulimia nervosa. The patient furthermore reported that she was repeatedly sexually abused by men at that time. She became pregnant at the age of 16 and gave birth to twins through vacuum extraction. Unfortunately, the procedure led to complications and serious health consequences for the patient. The manual removal of the second placenta led to a critical bleeding, 
resulting in a lack of fibrinogen. Altogether 14 units of stored blood had to be administered. Additionally, due to the heavy bleeding a supra-vaginal hysterectomy had to be performed. Because of the considerable and ongoing blood loss a second laparotomy was necessary and the left ovary was also removed. Following the delivery lactation did not occur. The entire secondary genital hair-growth did not grow again after its preoperational removal. Both children were put up for adoption immediately after birth.

When the patient was admitted to hospital four years later complaining of stomach pain, chronic hepatitis $\mathrm{C}$ was diagnosed. It was then that she was also diagnosed with Sheehan's syndrome: found was a secondary hypogonadism, an extensive loss of the pigmentation of the skin as a result of MSH deficiency, a secondary hypothyroidism and sinus bradycardia, as well as a secondary suprarenal gland insufficiency with reduced levels of glucocordicoids (and inconspicuous levels of mineralocorticoids).

Consequently, since the age of 21 , she had to have regular replacement therapy of thyroxine, prednisone, estradiol, and progesterone. Several years later it was noticed that the patient's serum was lipemic (neutral fat levels: $682 \mathrm{mg} \%$; cholesterol levels: $352 \mathrm{mg}$ $\%)$. The cause was her secret attacks of binge eating where she consumed vast amounts of fatty chocolates and ice-cream. At the age of 28 a cholecystectomy had to be performed. Until the age of 43 the patient was able to maintain a body weight of $51 \mathrm{~kg}$ being $1.56 \mathrm{~m}$ tall $\left(\mathrm{BMI}=20.9 \mathrm{~kg} / \mathrm{m}^{2}\right)$, and no episodes of $\mathrm{AN}$ were reported until then. A permanently observed leukocytosis (leukocyte count of $20,000 / \mu 1$ ) was attributed to the corticoid medication treatment. 
Overall, the patient did not complete any professional education and mostly lived on social benefits until she started a job as a child minder when she was 42 years old. She looked after the infant of an acquaintance and became deeply attached to the child. At the same time, however, she was very afraid that this new responsibility would be taken away from her. She became increasingly anxious and "forgot" to eat, which resulted in the extreme weight loss that led to her admission to hospital. Noteworthy is that the patient's fear of loosing her job had by then indeed become true: she was neither permitted nor capable to care for the child any longer.

At first it seemed that no difficulties were caused by the treatment she received at our psychosomatic unit. In order to treat the Sheehan's syndrome the hormone replacement referred to above, as well as the medical treatment for the successfully healed ventricular ulcer was continued. Furthermore, a hypochromic microcytic anemia was treated. She was able to maintain her weight of $33.7 \mathrm{Kg}$, but did not succeed in increasing it. The agreed care plan included that she was to be transferred and treated at the intensive-care unit if she started to loose weight again. Despite her own wish to receive psychosomatic treatment, the patient behaved rather aggressively and dismissively towards our staff. She boycotted agreements, secretly ate ice-cream and chocolate, and refrained from or delayed arranged medical examinations. She developed heavy flatulence and foul-smelling wind. 
Because of her low body weight we avoided the more confrontational elements of our psychodynamic setting; in particular group therapy. Instead we focused on the supporting and motivating individual therapy, silk painting, and guided relaxation exercises. When it became apparent that she indeed started loosing weight again, she discharged herself from hospital against her consultant's advice. One day after she discontinued her treatment with us she started to complain of severe stomach pains, profound watery diarrhoea, and vomiting. Four days later she was admitted to a different hospital suffering from an acute gastroenteritis. Nonetheless she still refused any intensive-care medical treatment and died as a result of toxic cardiac arrest. Noteworthy, only two days before her death she started to develop a high fever (between 39 and 40 ${ }^{\circ} \mathrm{C}$ ), and an increased leukocyte count of $28,000 \mu 1$.

The post-mortem examination confirmed a severe and acute gastroenterocolitis, including mucus membrane ulceration and intramural abscesses as well as a peritonitis. The mucosal relief was not recognisable in places. The histological examination of the hypophysis showed the loss of $95 \%$ of the adenohypophysis, and thus provided anatomic evidence of the diagnosed Sheehan's syndrome.

\section{Discussion}

The personal history of this patient has shown how psychological deprivation led to eating disturbances. Initial, and not always consented, sexual encounters led to early 
pregnancy. The life-threatening delivery of twins had tremendous consequences for the patient, resulting in Sheehan's syndrome, hepatitis C and a ventricular ulcer.

However, the case study also demonstrates something else: Despite the absence of the eating disorder for more than 20 years after its first appearance, a late exacerbation of it had occurred. The trigger was a psychosocial event, which was related to the patient's own personal history: The fear of losing the much loved infant she cared for must have reproduced painful memories of the loss of her own twins. From a psychodynamic perspective, looking after the child became a highly stressful, if not traumatic event, for the patient. This resulted in the AN to flare up again. At the same time, all intermittently acquired organic problems were also aggravated. It turned out that her manipulation of the treatment she received at our psychosomatic unit, especially the secretive binge eating of large amounts of chocolate and ice-cream, as well as the refusal to be medically examined, led to a fatal interaction of the various medical conditions, which had an exacerbating influence on each other. Non-anorexic patients would have probably reacted sooner with an increase in body temperature. Unfortunately, this infection defence mechanism is often only limited, or indeed not at all available anymore to patient suffering from $\mathrm{AN}^{13}$.

The patient presented a type of chronicity that proceeded covertly. An additional difficulty was that the bowel pathology of the patient (i.e. the ill-smelling wind) evoked a negative counter-transference reaction in the staff, which most likely led to a misconception of its medical validity (i.e. being a result of the enteritis). The importance to anticipate and effectively consider the phenomenon of transference and therapist 
countertransference while managing individuals with AN was already pointed out by Stober ${ }^{14}$ It is an aspect of in-patient care that, as we would like to stress, should not be underestimated. It can have tremendous consequences, as the case presented here demonstrates.

Palmer ${ }^{15}$ referring to Van Furth ${ }^{16}$ argues: "Good treatment should be the key to secondary prevention. However, solid evidence about how best to help patients is scanty although clinicians do their best and most patients recover." (p.1490). While Palmer ${ }^{15}$ and others ${ }^{17,18}$ dispute the claim that $\mathrm{AN}$ has the highest mortality rate amongst any psychiatric disorder, others ${ }^{19}$ confirm that individuals with AN indeed show a clinically important increase of premature death. This risk is even higher if the patient presents concomitant diseases ${ }^{9}$. While we agree with Van Furth ${ }^{16}$ that more evidence about better treatment options is indeed needed, we also would like to stress that one step of acquiring more knowledge is to gain an insight into the causes of death of patients with AN. In many cases the cause of death of patients with AN cannot reliably be established from clinical features alone.

We have demonstrated the existence of a complicated interaction between the disturbed psychosocial development of our patient, her frequent physical illness and the medical interventions she received. According to the recommendations of Derman and Szabo $^{12}$ any death of patients suffering from AN should be fully reported in order to improve treatment practices and thus preventing further pre-mature deaths. Further research is needed to gain a systematic overview between AN and other diseases. 
The authors express their gratitude to Dr Andreas Popp (Dept. of Pathology) for the performance of the autopsy, and to Dr Peter Semler (former head of the Dept. of Internal Medicine, Wenckebach Hospital Berlin) for the provision of his case notes. 


\section{References}

1. Gull WW. The address in medicine. The Lancet 1868;2:171-176.

2. Lasègue EC. De l'anorexie hystérique. Archive général de la médicine 1873;21,385403.

3. Lumsden DB, Alexander-Mott L. Understanding eating disorders. London: Taylor and Francis; 1994.

4. Simmonds M. Über Hypophysisschwund mit tödlichem Ausgang. Dtsch Med Wochenschr 1914;40:322-325.

5. Bergmann Gv. Magerkeit und Magersucht. Münch Med Wochenschr 1934;1:37-38.

6. Ryle JA. Anorexia Nervosa. Lancet 1936;2:893.

7. Farquharson RF, Hyland HH. Anorexia nervosa, a metabolic disorder of psychologic origin. JAMA 1938;111:1085

8. Sheehan HL. Postpartum necrosis of anterior pituitary. J Path Bact 1937;45:189-214.

9. Herzog W, Deter HC, Fiehn W, Petzold E. Medical findings and predictors of longterm physical outcome in anorexia nervosa: a prospective, 12-year follow-up study. Psychol Med 1997;27:269-279.

10. Deter HC, Herzog W. Anorexia nervosa in a long term perspective: results of the Heidelberg-Mannheim-study. Psychosom Med 1994;56:1-9.

11. Zipfel S, Löwe B, Reas DL, Deter HC, Herzog W. Long-term prognosis of anorexia nervosa: lessons from a 21-year follow up study. The Lancet 2000;355:721-722. 
12. Derma T, Szabo CP. Why do individuals with anorexia nervosa die? A case of sudden death. Int J Eat Disord 2006;39:260-262.

13. Birmingham CL, Hodgson DM, Fung J, Brown R, Wakefield A, Bartrop R, Beumont P. Reduced febrile response to bacterial infection in anorexia nervosa patients. Int $\mathrm{J}$ Eat Disord 2003;34:269-272.

14. Strober M. Managing the chronic, treatment-resistant patient with anorexia nervosa. Int J Eat Disord 2004;36:245-255.

15. Palmer RL. Death in anorexia nervosa. The Lancet $2003 ; 361: 1490$

16. Van Furth EF. The treatment of anorexia nervosa. In: Hoek WH, Treasure JL, Katzman MA, editors. Neurobiology in the treatment of eating disorders. Chichester: Wiley \& Sons, 1998, p. 315-330.

17. Korndorfer SR, Lucas AR, Suman VJ, Crowson CS, Krahn LE, Melton LJ, (3 ${ }^{\text {rd }}$ ed). Long-term survival of patients with anorexia nervosa: A population-based study in Rochester. Minn. Mayo Clinic Proceedings 2003;78:278-284.

18. Sullivan PF. Discrepant results regarding long-term survival of patients with anorexia nervosa. Mayo Clinic Proceedings 2003;78:273-274.

19. Birmingham CL, Su J, Hlynsky JA, Goldner EM, Gao M. The mortality rate from anorexia nervosa. Int J Eat Disord 2005;38:143-146.

This is the pre-peer reviewed version of the following article: FULL CITE, which has been published in final form 